\title{
Guide to supporting agricultural NDC implementation: GHG mitigation in rice production in Vietnam
}

\author{
Katherine M. Nelson ${ }^{1 *}$, Bui Tan Yen ${ }^{1}$, Bjoern Ole Sander ${ }^{1}$ \\ ${ }^{1}$ International Rice Research Institute, Hanoi, Vietnam \\ *Corresponding author: k.nelson@irri.org
}

\begin{abstract}
The agriculture sector contributes significantly to national greenhouse gas emissions in developing countries. Rice is a major contributor to methane emissions in Asia and many countries have recognized the potential to reduce emissions by including rice in their nationally determined contributions. This guide serves to bridge the gap in knowledge on developing and implementing action plans to achieve the ambitious targets to reduce emissions in rice. With a focus on Vietnam, this guide describes methods and tools for research organizations to support national governments to plan, finance, and implement mitigation actions in the rice sector.
\end{abstract}




\section{INTRODUCTION}

Agriculture contributes significantly to greenhouse gas (GHG) emissions globally, especially in industrially developing ("transforming") economies that are currently heavily dependent on income from agriculture, such as Vietnam. The country has identified agriculture-related emission reduction commitments for its Nationally Determined Contributions (NDCs) in the Paris Agreement (NDC, 2020). However, methods for transitioning from commitments to developing and implementing action plans for agricultural NDCs have not been well documented. Concrete, actionable, and replicable methods to understanding and measuring mitigation scenarios are necessary for planning and targeting investment strategies in order for national governments to move beyond "business as usual" scenarios to meeting their NDC commitments with financial and implementation support from international organizations.

The purpose of this document is to serve as a guide for research to support national partners to plan, finance, and implement the agricultural NDCs. This is a summary of the collaborative and evolving process initiated by the partnership between the International Rice Research Institute (IRRI) and the Ministry of Agriculture and Rural Development (MARD) of Vietnam.

As the third largest exporter of rice globally, Vietnam's rice sector is a major contributor to national greenhouse gas emissions, surpassing the transport sector (MONRE, 2014). Vietnam ranks globally as one of the countries most affected by climate change and this will only worsen in the future, leaving millions vulnerable to natural disasters and food insecure.

Efforts to reduce GHG emissions from rice production are a national priority for achieving Vietnam's NDCs. Unlike the livestock industry where the animal itself is responsible for the majority of emissions, in rice production it is not the plant per se that is the culprit of GHG production, rather it is the way in which the crop is grown and managed that makes a difference in the amount of GHGs emitted. The single largest factor influencing the amount of GHG emitted from rice production is the management of water1. The process of alternating between wet periods and dry periods during rice production is herein referred to as alternate wetting and drying (AWD), which has been proven to reduce GHG emissions in rice production by 30\%-70\% without affecting yields (Carrijo et al., 2017). Given that changes in water management represent the highest potential to mitigate GHGs in rice production, the following sections will explain the process of actions needed to define suitable areas, plan, and target investment for achieving the NDCs. This document details the process for engaging national partners and supporting agricultural NDC implementation (see Figure 1).

Roadmap to NDC implementation:

- Map suitable area for AWD (climatic suitability and adoption capacity)

- Validate and merge maps through participatory verification process to define target regions

- Perform cost-benefit analysis for mitigation strategies based on maps

\footnotetext{
${ }^{1}$ Additional factors that contribute to GHG emissions include fertilizer, crop duration, residue/ post harvest management, and on-farm fuel use
} 
- Calculate GHG emissions of rice production area and model reduction scenarios

- Standardize methods for measuring, reporting, and verification

- Collaborate with national partners to develop investment plans to take NDC actions to scale

- Create long-term financial plans for securing funding to achieve NDCs

- Secure funding sources for next stages of NDC action

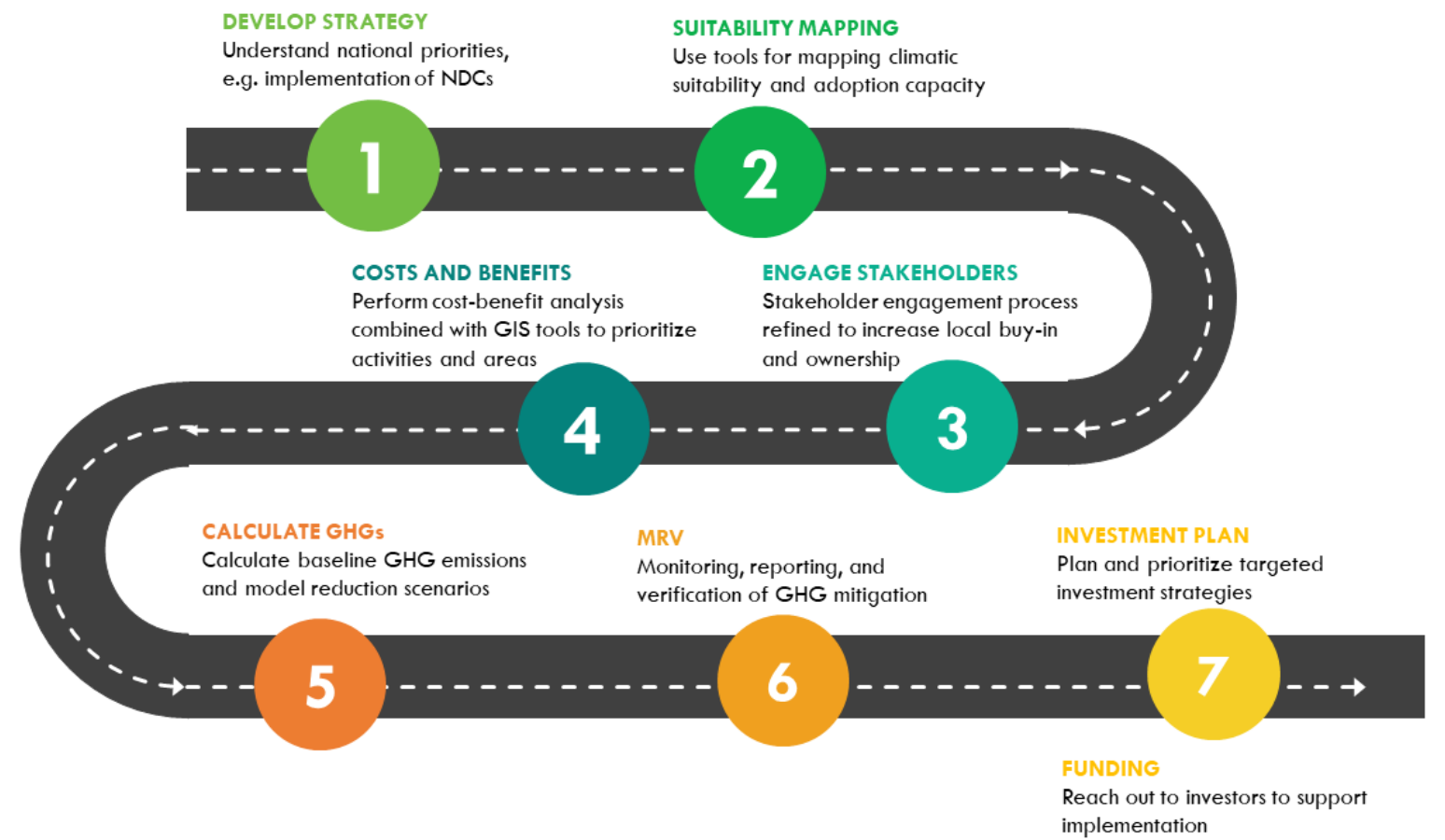

Figure 1 Roadmap to NDC implementation

\section{Mapping suitable rice land for AWD implementation}

Starting in 2006, IRRI has been in partnership with national research institutions, to develop and pilot AWD in Vietnam. In 2016, AWD has been identified as a promising practice for GHG mitigation and selected as an option in the Vietnam NDCs. However, there was no previous science-based approach that could be used to identify where and when AWD could be applied. To support Vietnam's agricultural NDC implementation, IRRI has tested a methodology to identify spatial and temporal climatic suitability for AWD application in the country. The methodology has been adapted to map AWD suitability for the whole country and then this process has been applied to regional and provincial levels.

Sub-sections below summarize the case study of An Giang, a representative rice production province in the Mekong River Delta. The AWD suitability analysis consists of 4 steps:

1. Develop suitability maps based on climatic and biophysical factors that affect the application of AWD (i.e., rainfall, topography, soil type, etc)

2. Develop adoption capacity maps based on human factors that affect the application of AWD (i.e., irrigation infrastructure, farmer knowledge, institutional capacity) 
3. Merge the maps to create an overall AWD suitability map for the region

4. Verify the content and assumptions of the overall AWD suitability map with local officials

In the first step, planted area of rice is mapped based on statistical land-type data, rice cropping calendar and remote sensing images. Climatic factors including rainfall, potential evapotranspiration and soil percolation rate of rice land were then used to assess the water balance. A suitability score was assigned to each area unit based on the number of water deficit dekads2 during a rice season. The overall score was classified into three groups representing: high suitability (green), moderate suitability (yellow) and low/no suitability (red). Figure 2 shows maps of climatic AWD suitability in winter-spring, summerautumn and autumn-winter seasons of An Giang province.

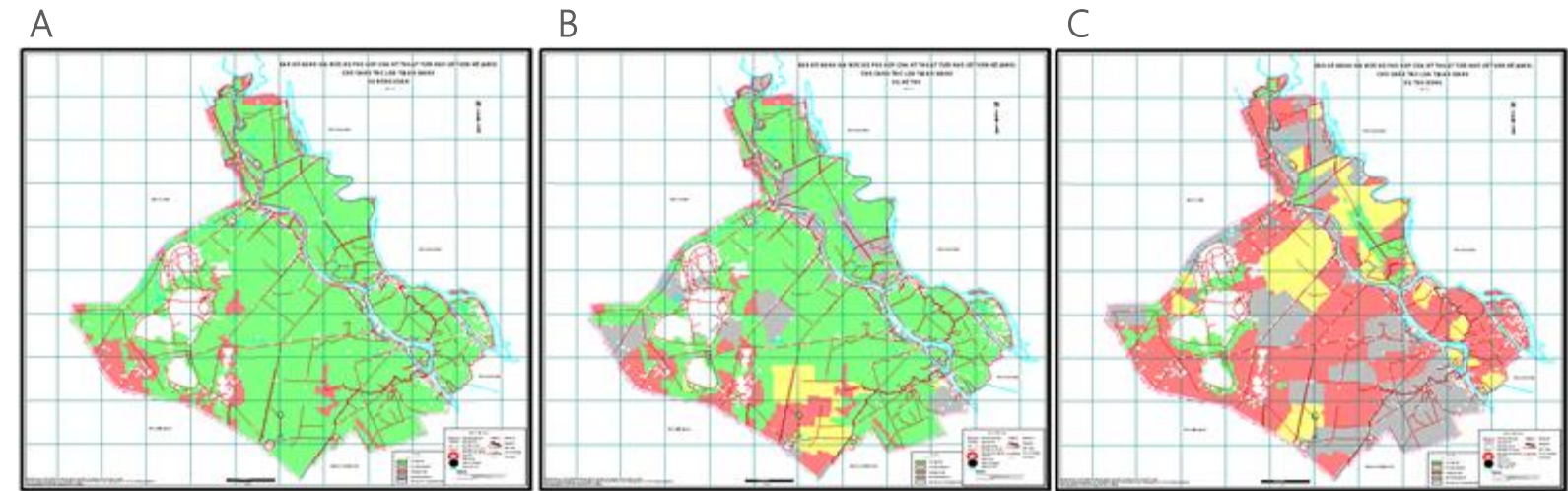

Figure 2 An Giang Province AWD climatic suitability maps for (a) winter-spring season, (b) summer-autumn season and (c) autumnwinter season. Green color represents high suitability, yellow is moderate suitability, red is low or no suitability, gray color means no rice is planted, and white color means other land-use types.

The second step focuses on evaluation of human factors that influence the adoption capacity for AWD. In this step, human factors and influences were identified through discussions with key personnel from local agencies under the Department of Agriculture and Rural Development (DARD) and researchers from national research institutes. In the case of An Giang, the four human influencing factors were taken into evaluation, including: canal irrigation infrastructure, drainage capability, farmer awareness of the technology, and cooperative authority.

Table 1 Scoring factors for AWD adoption capacity

\begin{tabular}{|c|c|c|c|}
\hline Canal infrastructure & $<30 \%$ concrete canal & $30 \%-50 \%$ concrete & $>50 \%$ concrete \\
\hline $\begin{array}{l}\text { Drainage capability } \\
\text { (combination of flooding, } \\
\text { rainfall, pumping stations) }\end{array}$ & $\begin{array}{l}\text { Seasonally low drainage } \\
\text { capability }\end{array}$ & $\begin{array}{l}\text { Seasonally moderate } \\
\text { drainage capability }\end{array}$ & $\begin{array}{l}\text { Seasonally high drainage } \\
\text { capability }\end{array}$ \\
\hline Farmer awareness & $\begin{array}{l}\text { Unaware or unwilling to } \\
\text { adapt }\end{array}$ & $\begin{array}{l}\text { Some awareness but lack } \\
\text { ability or motivation }\end{array}$ & Aware and willing to adapt \\
\hline Cooperative authority & Low authority - farmers & Moderate authority - & High authority - farmers \\
\hline
\end{tabular}

${ }^{2}$ A dekad is a 10 days period 


\begin{tabular}{|lll|}
\hline $\begin{array}{l}\text { don't follow rules/ } \\
\text { recommendations }\end{array}$ & $\begin{array}{l}\text { farmers rarely follow rules/ } \\
\text { recommendations }\end{array}$ & $\begin{array}{l}\text { follow rules/ } \\
\text { recommendations }\end{array}$ \\
\hline
\end{tabular}
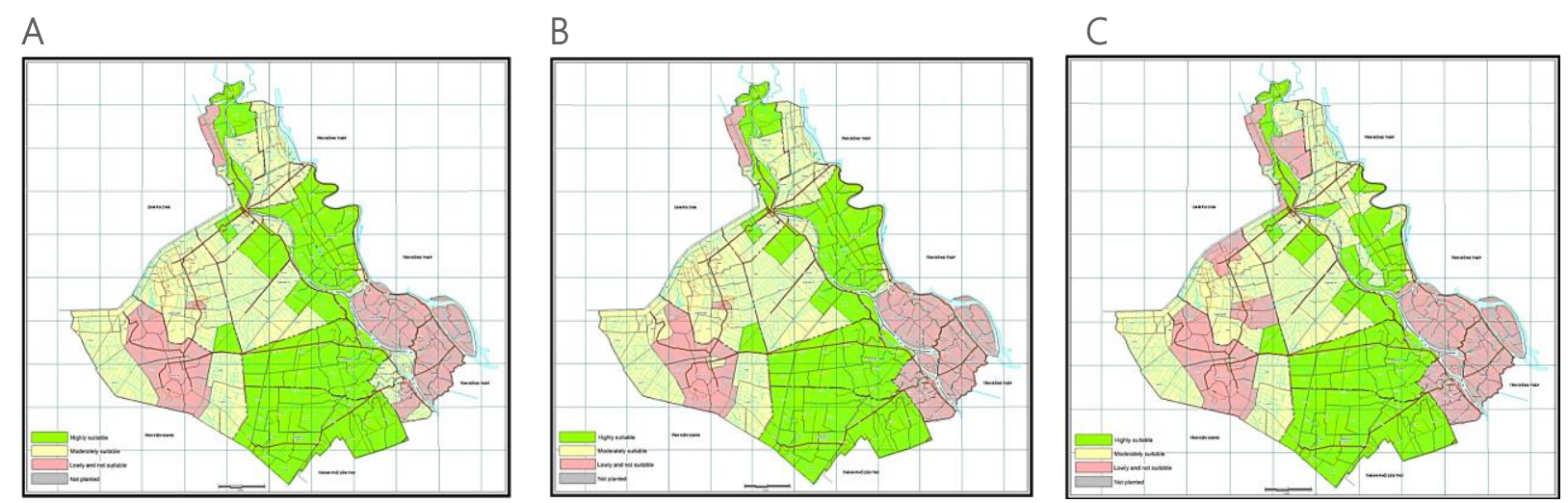

Figure 3 Adoption capacity maps for (a) winter-spring, (b) summer-autumn and (c) autumn-winter season of An Giang province. Green color represents high adoption capacity, yellow is or moderate capacity, red is low capacity.

A scoring method was used to rate the factors for each commune. The list of adoption factors and ratings are shown in Table 1. Each factor was scored on a scale from 1-10, with 1 representing low capacity and 10 being high capacity in that category. Based on the final rating score, AWD adoption capacity maps (Figure 3) were classified into three groups, i.e. high, moderate, and low capacity. In total 22 DARD staff, two staff from each of the 11 districts in An Giang Province, scored each commune in their respective districts (for a total of 149 communes) according to the adoption capacity criteria.

In the third step, seasonal climatic-suitability maps and adoption capacity maps are combined to generate overall suitability maps. There is an assumption that the climatic and adoption factors have equal weighted value. Therefore, the average weighted method was applied to calculate overall suitability score, again classified as high, moderate and low suitability and represented by the colors green, yellow, and red, respectively (Figure 5).

In the last step, the overall AWD suitability maps are verified through a participatory feedback process. This was conducted in An Giang Province with participation of provincial and district officials of DARD. In this process, local officials were asked to review suitability levels for each of the three seasons (see Figure 4). Updates of improved infrastructure, recent land-use changes, water saving practices applied in last seasons, and other local knowledge were used to verify suitability levels. In general, suitability levels in most of the rice land of the province were accepted by participants. Suitability levels in some areas were adjusted with consultation of local officials. 

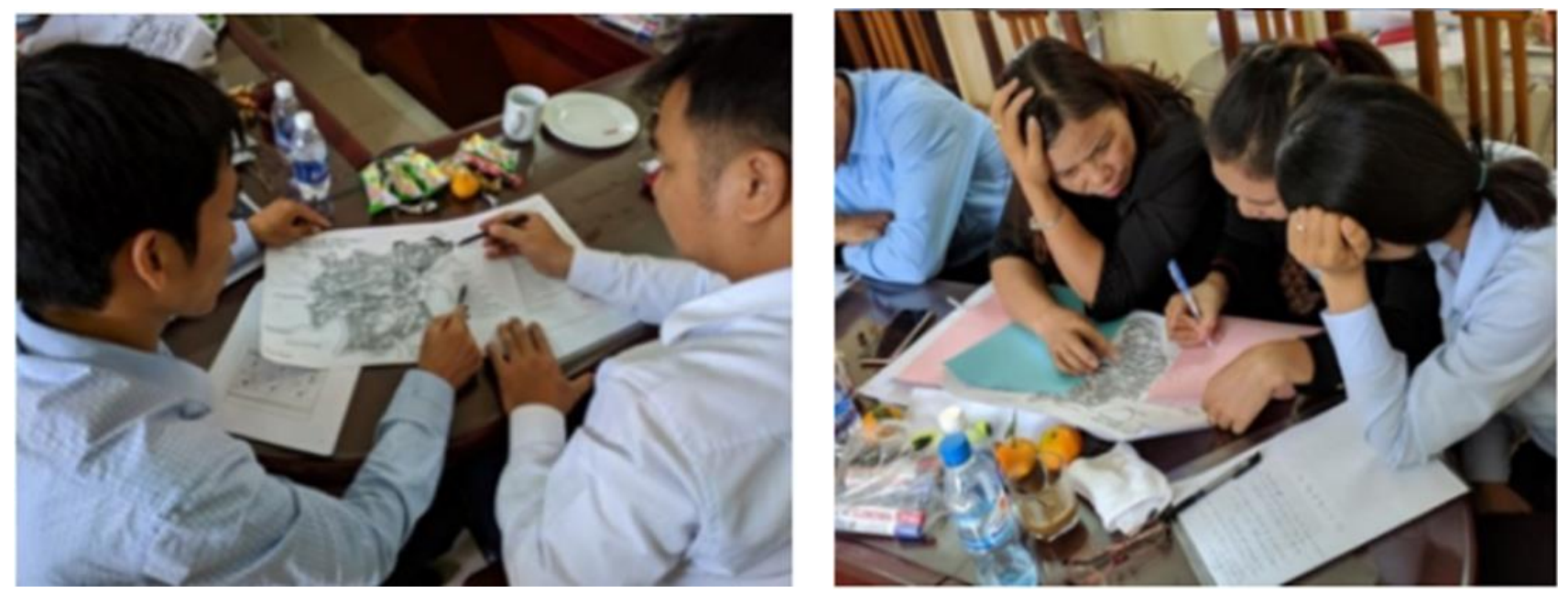

Figure 4 Photos of the participatory verification and feedback sessions for AWD suitability mapping.

After feedback from local stakeholders, the overall AWD suitability maps are finalized. Figure 5 shows the final verified AWD suitability maps for three rice seasons of An Giang province. The AWD suitability maps were officially transferred to An Giang DARD with representatives from the Department of Crop Production from 8 provinces in the Mekong River Delta attending.

To date these maps are the best reference to support AWD implementation plans. This process can be applied to other provinces of Vietnam, as well as in other countries, to put the NDC commitments into action at the regional and local level. At meso- and macro levels, the AWD suitability analysis method together with GHG measurements can be applied to assess the potential for regional and national GHG mitigation in the rice sector.
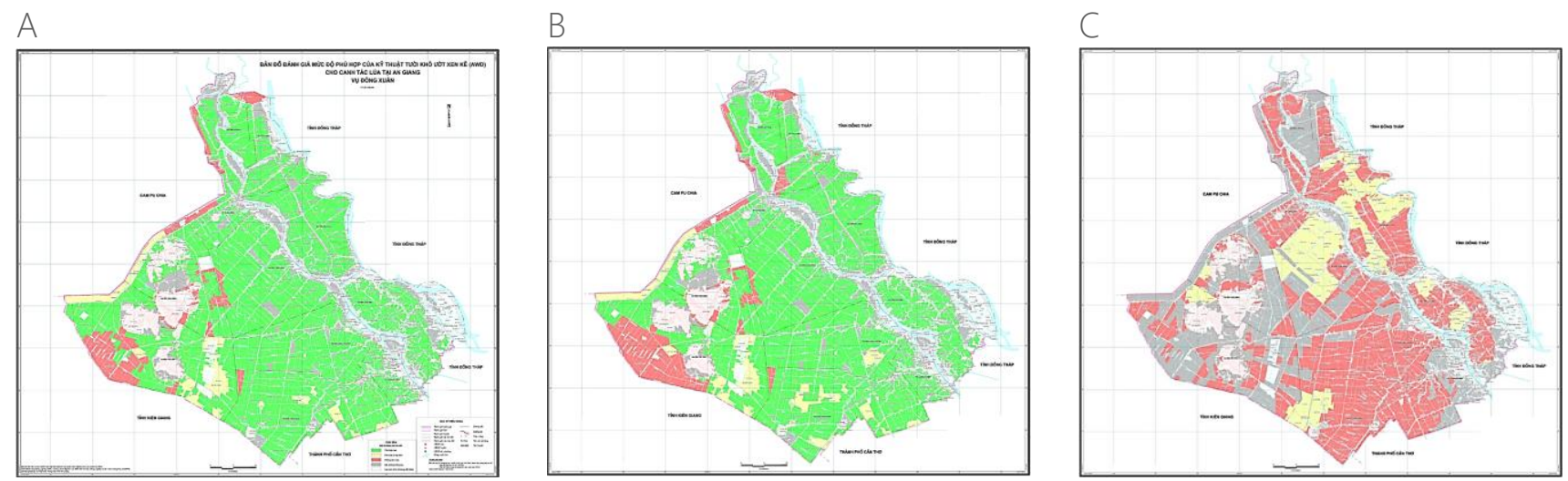

Figure 5 Overall AWD suitability maps for (a) winter-spring, (b) summer-autumn and (c) autumn-winter season of An Giang province. Green color represents high suitability, yellow is moderate suitability, red is low suitability, gray color means no rice is planted, and white color means other land-use type.

\section{Cost-benefit analysis (CBA)}

In spite of ample evidence on the technical feasibility of GHG mitigation in rice production, the adoption of these practices still remains fragmented at the country scale. One of the reasons for the slow uptake of mitigation practices is a lack of reliable data on related costs and benefits which can be used by planning departments and implementation organizations to help target technical capacity needs and 
infrastructure development. There are multiple strategies for assessing costs and benefits which can be done at the farm-level or aggregated to regional and national scales. Different purposes require different methods and choosing the right methodology depends on the level of intervention and expected outcomes for the project.

Farm-level cost-benefit analyses are useful if the goal is to understand the financial costs or savings incurred by farmers using a particular mitigation technology. These can then be useful to guide the development of carbon payment schemes or subsidies. At the national level, if the goal is to determine the appropriate agricultural technologies and practices to promote over the long-term that will benefit farmer livelihoods and have high mitigation potential, the marginal abatement cost curve (MACC) methods can be good options to weigh trade-offs between different technologies and their business as usual options (Escobar Carbonari et al., 2019). However, if the goal is to calculate the highest mitigation impact-to-cost ratio in order to reach the NDCs, project investment analyses are necessary as these include the required implementation costs for infrastructure development, capacity building (i.e., training of farmers on the technologies), and expenses related to taking baseline measurements, monitoring, reporting, and verifying farmer practices and the resulting emission reductions. These are all part of the process of transitioning to low-emission production and are an essential part of proving the emission reductions in a transparent and standardized way that is accepted for NDC reporting so they cannot be omitted from national level cost-benefit analyses. Cost-benefit analyses and MACCs that do not incorporate project implementation costs run the risk of being misinterpreted and can be misleading at best and detrimental for mitigation (and funding) at worst.

\section{Measuring GHG emissions}

In addition to the collection of in-field closed-chamber gas measurements, farm-level surveys have been designed, tested, and refined to elicit the management information needed to estimate GHG emissions on an individual, regional, and national level following the International Panel on Climate Change (IPCC) guidelines. The SECTOR tool, developed to be a user-friendly GHG calculator, requires inputs on crop areas, duration, yields and management. The tool offers a high range of flexibility in terms of entering newly obtained emission factors, easy data transfer from crop statistics for entering activity data and detailed specifications of GHG scenarios, as well as providing the ability to select a range of scales for aggregation (Wassman et al. 2019). Moreover, SECTOR provides a streamlined framework for accelerated data input that will facilitate rapid assessments of multiple scenarios for domains with many spatial units.

\section{Monitoring, reporting, verification (MRV)}

MRV is a concept that integrates three independent processes of GHG emission mitigation initiatives; of which (M) involves measuring and monitoring GHGs emission from paddy rice fields, (R) includes reporting and calculating emissions, and (V) verifying results from monitoring, reporting, and calculation activities (verification often refers to third party auditing results but other verification processes may be explored, such as satellite remote sensing and digital sensors, to prove mitigation 
activities). The "measuring" component includes the measurement of baseline conditions and is imperative to the process.

Although MRV is an important part of the NDC implementation process to ensure compliance with international UNFCCC reporting requirements to track emissions and emissions reductions, a national standardized and transparent protocol for reporting emission reductions in rice production that is suitable for the NDCs has yet to be defined. MRV guidelines exist for certified emission reductions through the UNFCCC Clean Development Mechanism but these MRV requirements are far too strict and economically infeasible to be used for NDC reporting.

The Prime Minister of Vietnam approved the national program on greenhouse gas emission management and management of carbon credit business activities3. The main targets of this program include strengthening the capacity of ministries, sectors and localities for national greenhouse gas inventory; and developing the measurement, reporting, verification system (MRV). IRRI is working together with national and local governments and the implementing agencies to develop MRV systems to meet the following objectives: improve the basis of information and the monitoring of rice-related mitigation actions, coordinate individual mitigation activities, and track emission reductions.

In the rice sector, the Ministry of Agriculture and Rural Development (MARD) has prioritized the AWD practice as a key mitigation action in Vietnam's NDC implementation plan. In line with the national target, IRRI is supporting MARD to establish an MRV system for mitigation actions in the rice sector through the development of a provincial rice production statistical reporting system. This approach expands the existing reporting system to monitoring of additional rice crop management factors and it is being piloted by the provincial Department of Agriculture and Rural Development (DARD) in An Giang province in 2021 (see Figure 6).

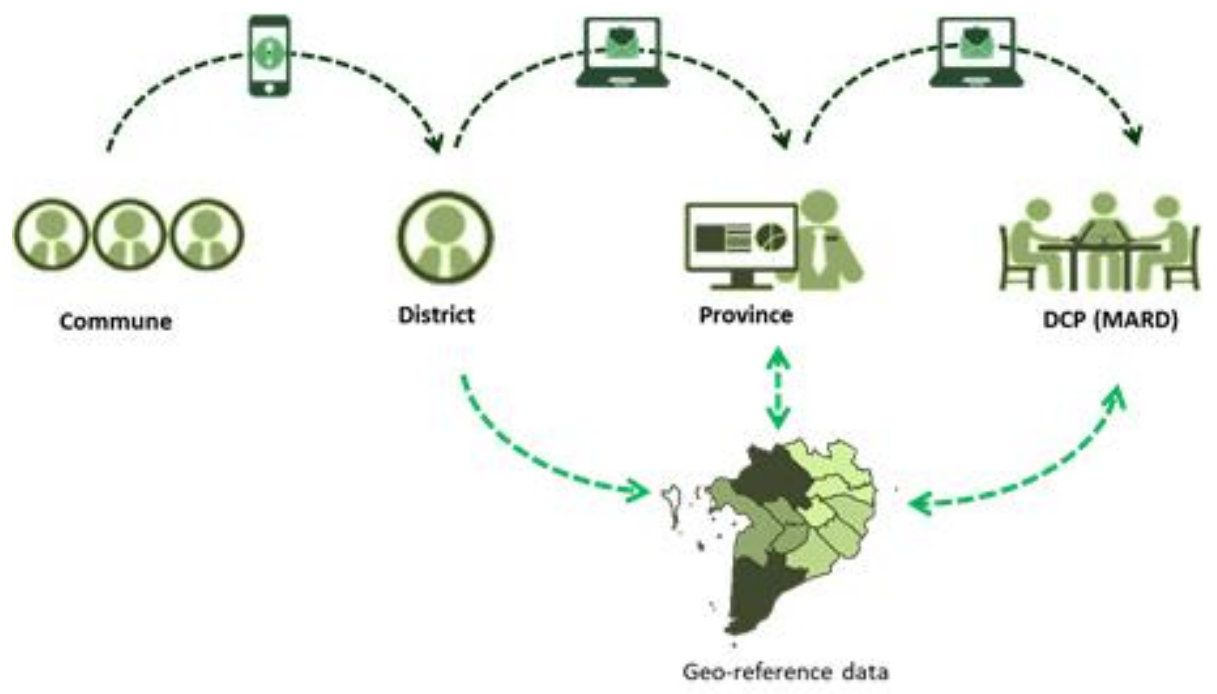

Figure 6 The flow of information in the MRV system for rice management factors

\footnotetext{
${ }^{3}$ Decision 1775/QD-TTg issued on 21 November 2012
} 
By integrating water management of rice crops into this system, the area of AWD adoption can be monitored and reported. A GIS plug-in component is also being developed to quickly map the distribution of monitoring variables (e.g. transplanting area, rice varieties, AWD adoption, climate risks and yield loss).

Once the pilot has been proven successful, other mitigation options (e.g. fertilizer deep placement or adjusted rice straw management) can be easily incorporated. This MRV system is specific to the Vietnamese context, but it could be adjusted for relevance to other country contexts. Additionally, the MRV development process can be applied and adapted to other agricultural, forestry, and other land use (AFOLU) mitigation activities.

\section{Investment plan for up-scaling}

Finance is critical for the implementation of the mitigation and adaptation actions set out in countries' NDCs. Many of the NDCs submitted include conditions for their full implementation, such as additional or enhanced international support in the form of finance, technology transfer, technical assistance and capacity-building. In order to access finance, countries need clear project concepts at a minimum, and financing propositions need to be developed. This involves securing bilateral and multilateral grants to work together with the national government on developing and implementing agricultural NDCs, as well as being able to attract private investment.

NDC actions should be prioritized based on capital costs (e.g. infrastructure), ongoing maintenance costs, capacity-building or training, and the human resources needed to implement, monitor, report, and verify the actions. The aforementioned tools for suitability mapping of mitigation options, cost-benefit analyses, GHG emission calculation and MRV support this decision-making process.

Existing domestic support should be identified, for example through the national climate strategies and agricultural reform strategies, in addition to expected bilateral and multilateral support. Once potential bilateral, multilateral, and private funding sources that the country already has a history of accessing funds have been identified, these organizations should be approached first for short-to-medium term financing for priority NDC activities. In parallel, new sources of finance that could support NDC actions should be identified and assessed according to the eligibility of each action against the funding criteria.

Project pipelines can be identified, prioritized, and developed through the use of a wide range of planning and decision-making tools mentioned in this document. Viable opportunities can then be developed into funding proposals for approaching bilateral, multilateral, and private sector funders, such as the Global Environmental Facility (GEF), the International Climate Initiative of the German government (IKI) or the Green Climate Fund (GCF).

\section{Conclusions}

Vietnam has recently updated their NDC to $9 \%$ reduction in GHG emissions by 2030 with national capacity, and to $27 \%$ with sufficient international support (NDC, 2020). Although AWD and straw 
management have been identified in Vietnam's NDCs as key options in the agriculture sector that could significantly contribute to national GHG mitigation, farmer adoption at scale and the ability to track field-level practices in rice production are still limited. Without significant research and development support to identify suitable regions, target financial investments, secure international funding, remove barriers, and provide reliable MRV systems, the national targets for the rice sector are unlikely to be achieved.

To move towards achieving these mitigation goals in Vietnam and elsewhere, governments, NGOs, research organizations, and the private sector can utilize the myriad of tools mentioned herein that have been developed specifically for rice production to i) define high priority regions for various NDC actions in the agriculture sector, ii) develop the MRV framework, iii) establish the associated financing strategies for these actions, iv) conduct scoping studies to provide evidence-based mitigation packages that are finance-ready, and v) secure financing from multiple funding sources (including bilateral, multilateral, and private industry sources). 


\section{References}

Carrijo, D.R., Lundy, M.E. and Linquist, B.A., 2017. Rice yields and water use under alternate wetting and drying irrigation: A meta-analysis. Field Crops Research, 203, pp.173-180.

Escobar Carbonari, D., Grosjean, G., Läderach, P., Nghia, T.D., Sander, B.O., McKinley, J., Sebastian, L. and Tapasco, J., 2019. Reviewing Vietnam's Nationally Determined Contribution: A New Perspective Using the Marginal Cost of Abatement. Frontiers in Sustainable Food Systems, 3, p.14.

MONRE, 2014. The Initial Biennial Updated Report of Vietnam. Hanoi: MONRE.

NDC, 2020. Viet Nam's updated nationally determined contribution. Available at: https://www4.unfccc.int/sites/ndcstaging/PublishedDocuments/Viet\%20Nam\%20First/Viet\%20Nam_N DC_2020_Eng.pdf. Accessed on July 7, 2021.

UNFCCC Consultative Group of Experts. 2019 Technical handbook for developing country Parties on preparing for implementation of the enhanced transparency framework under the Paris Agreement. Technical Handbook, UNFCCC.

https://unfccc.int/sites/default/files/resource/ETF_technical\%20handbook_First\%20Edition.pdf

UNFCCC, 2020. Reference Manual for the Enhanced Transparency Framework under the Paris Agreement. https://unfccc.int/sites/default/files/resource/ETFReferenceManual.pdf

Wassmann, R., Pasco, R., Zerrudo, J., Ngo, D.M., Vo, T.B.T. and Sander, B.O., 2019. Introducing a new tool for greenhouse gas calculation tailored for cropland: rationale, operational framework and potential application. Carbon Management, 10(1), pp.79-92. 